\title{
Negative Symptom Assessment-16 Clinical Classification
}

National Cancer Institute

\section{Source}

National Cancer Institute. Negative Symptom Assessment-16 Clinical Classification. NCI

Thesaurus. Code C121009.

A standardized rating scale developed by Axelrod et al in 1993, which is a classification system used to assess the presence, severity, and various neg ative symptoms associated with schizophrenia. This instrument contains 16 items and the characterization of negative symptoms is based on a 5-factor model: communication, emotion/affect, social involvement, motivation, and retardation. 